\title{
STRONG MOTION EARTHQUAKE RECORDING IN NEW ZEALAND
}

\author{
R. I. Skinner*, W. R. Stephenson*, R. T. Hefford*
}

An extensive network of strong-motion accelerographs is installed on the ground throughout New Zealand and also in major structures. At present this system contains 77 threecomponent recorders and 74 two-component non. timebase recorders. Since severe earthquakes are rare, and their violence may be very different at nearby positions, the strong-motion arthquake records must be supplemented by seismological, geological and geophysical data in order to obtain adequate information for the design of earthquake-resistant structures.

In choosing the number and location of accelerographs it is necessary to consider carefully the ways in which their records will be used in the design of structures and in the assessment of damaged structures。 Network planning will also be influenced by the availability of jnformation which can supplement strong-motion records.

Ground accelerations are a direct measure of the inertia attack on structures and on their supporting ground. Measured and deduced ground accelerations are, therefore, the primary data on which efficient earthquakeresistant design must be based.

Extrapolation from measured accelerograms becomes much more accurate if it is possible to distinguish between source effects, rock transmission effects, and local ground effects. In particular source effects can be related to the long and systematic seismological record of source magnitudes and characters. Strong-motion recorder sites should be located on nearby rock as well as on typical ground in order to assist in separating source, transmission, and local effects. The New Zealand network is at present deficient in accelerographs located on rock.

In addition to the provision of a countrywide distribution and to the selection of ground conditions at the sites, a number of other factors must be considered in the detail ed choice of the locations of accelerograph sites. Cities, towns, and major construction areas are preferred locations as accelerograms recorded at these places are more directly applicable to local structures. Furthermore, the measured accelerations assist in the study of local earthquake-damaged structures. Again more convenient sites are available in builtup areas.

Those areas occupied by major cities justify a denser network of accelerographs to measure local microzone effects. Again the

* Physics and Engineering Laboratory, Department of Scientific and Industrial Research, Lower Hutt, New Zealand. infrequency of severe earthquake necessitates the use of supplementary measurements, data, and analysis. These supplementary technieques include the measurement of frequent low-intensity earthquakes to enable the deduction of local modifications to the accelerations during rare moderately-severe earthquakes. During very severe earthquakes flexible ground will change character and may fail. In order to deduce these microzone effects geophysical, geological, and soil mechanics studies must be made. At present systematic groups of three-component accelerographs have been installed in wellington, ( 9 instruments), and in the Hutt Valley (? instruments).

After the measurement of ground acceleration to obtain the inertia attack the second major task of strong-motion accelerographs is to measure the response of structures during severe and damaging earthquakes. As in the case of the ground accelerograph network auxiliary measurements and data are required. Corresponding to the small earthquake measurements on the ground are measurements of the dynamic character of buildings, using a building shaker. There are 9 buildings containing 3 or more accelerographs, 8 of which are interconnected to give simultaneous starting and common time marks.

A somewhat neglected field of measurement is the relative ground displacements which occur during severe earthquakes. Although some information can be obtained by double integration errors are introduced in the computed longer period displacements by errors in baseline determination and by errors due to gravity forces on the tilted accelerographs. The latter is a basic source of error which can only be removed by recording the two components of accelerograph tilt throughout the duration of the earthquake.

\section{Strong-Motion Accelerographs in Buildings}

The type Mo2 3-component accelerograph is the primary recorder for the New Zealand strongmotion network. This is a 3-component timebase accelerograph which records high-definition traces on unperforated $35 \mathrm{~mm}$ film. The precision time marks at 0.02 second intervals define an appropriate interval at which to read the traces. Starting is initiated by a vertical sensing geophone. The cassette holds sufficient film for 9 records, each of 47 seconds duration or for 5 records of 70 seconds duration.

A11 MO2 accelerograph sensing units are given a series of precision static tests. These tests give the calibration scaling factor for each trace and the small departures of the sensing axes from their nominal directions. 
32

They also measure the Iinearity and repeatabil. ity of sensor outputs. The measurements and computer calculations are highly mechanised and self checking. Dynamic tests are made on a sample basis. When an earthquake record has been digitized it may be adjusted for sensitivity and corrected for small departures from nominal sensing directions by the simple procedure described in the M02 Operating Manual.

An essential adjunct to these MO2 accelerographs is an efficient method of digitising the recorded accelerograms. The laboratory uses a projector-based digitiser which punches the trace ordinates on 8-hole paper tape. The system was specifically designed to digitise MO2 accelerograms. The three component traces and the reference trace can be digitised at 0.02 second intervals with a reading time of 10 minutes per second of the 4 -trace record. The type MOZ accelerograph is described in some detail in the MO2 Installation and Operating Manual, available from the manufacturer.

Low-cost non-timebase accelerographs, types SP1 and SP2 are installed at 74 sites throughout New Zealand. The S.P. accelerograph traces the end-point of the vector of the horizontal acceleration as a "clover-leaf" pattern on a smoked glass plate.

An earlier form of the 3-component acce1erograph, the type MO1, and the non-timebase accelerograph, type SP2, are described in a paper by Duflou and Skinner (1965). Their general appearance is shown in Figs. 4 (a) and $4(\mathrm{~b})$.

The progressive installation of the above accelerographs throughout New Zealand is shown in Table $I$.

TABLE 1

Installation of Accelerographs in New Zealand

\begin{tabular}{|c|c|c|c|}
\hline Year & Type SP & Type MO1 & Type MO2 \\
\hline 1963 & 16 & & \\
1964 & 47 & & \\
1965 & 59 & & \\
1966 & 72 & 7 & \\
1967 & 71 & 7 & \\
1968 & 70 & 9 & 22 \\
1969 & 71 & 13 & 45 \\
1970 & 74 & 20 & 57 \\
\hline
\end{tabular}

New Zealand-wide Network of Accelerographs

From 1955 to 1963 a network of early types of strong-motion accelerographs was operated in New Zealand. Five 2-component accelerographs using electronic valve amplifiers were operated until 1959, but standby power systems gave difficulties in the field. These were replaced by 6 mechanical 2-component recorders which used a large mass and mechanical I inkages to a waxed paper recorder. These were generally successful and gave satisfactory records of the 10 April 1962 Westport earthquake and its larger aftershocks.
In 195536 simple peak-reading accelerographs were installed. 18 of these were inverted pendulums which recorded on smoked glass and 18 were sets of 6 weights graded to topple at various horizontal accelerations.

The mechanical triggers to indicate toppling of the weights gave serious trouble. However, the inverted pendulums showed consid. erable promise and now exist in a modified form as the type SP accelerographs. In addition to some valuable strong-motion records the operation of these early instruments gave valuable field experience. The requirements of adequate sites were explored, including the need for protection from external shock, and inadvertent disturbance by inquisitive people. The peak reading accelerographs are particularly vulnerable to occasional non-earthquake disturbances as such disturbances are recorded on top of any earthquake which occurs.

From 1963 to 1966 the earlier non-timebase accelerographs were replaced by 72 of the improved inverted pendulum type (SP1 and SP2). Their locations are shown in Fig. 2. These lowcost accelerographs have proved generally satisfactory in service。

The present network of 3 component accelerographs of types MO1 and MO2 has been built up since 1966 with the annual build up shown in Table I. The locations of these accelerographs are shown in Fig. 1. These accelerographs have performed very well in the field. Experience with the earlier networks, in which all the accelerographs were sited "indoors", enabled us to choose sites without excessive vibration. At these sites the accelerographs were given adequate protection and security.

During the initial stages some difficulties were experienced with the dry battery power supplies and the MOl at Westport failed to record the main shock of the Inangahua earthquake on 24.5 .68 . With a renewed battery all the larger aftershocks were recorded successfully. A more reliable type of dry battery has been adopted and a strict schedule of service visits at 6-month intervals instituted. Checks reveal that MO accelerographs at indoor sites are now close to $100 \%$ operational. They have in fact recorded all earthquakes of sufficient size to ensure triggering.

Some 20 type MO2 accelerographs have been installed at "outdoor" sites. These have typically consisted of a 3 foot by 3 foot slab of concrete set below ground level, with a one foot high concrete plinth on which the accelerograph is mounted and to which a locked cover box is attached. Humidity problems arose at some outdoor sites and these were overcome by ventilating the cover boxes and placing a dry ing agent within the accelerograph. Recent service visits have established that instruments at outdoor sites are now close to $100 \%$ operational。

The non-timebase SP accelerographs have played a valuable role in the network. Although limited in accuracy they have given records at many points for which a comprehensive accelerograph was not available. When installed beside other accelerographs they have provided a valuable back-up. The main shock of the 1968 Inangahua earthquake was recorded on SP accelerographs at westport and at several other 
While the use to which SP records can be put is strictly limited they do give the amplitude, direction, and number, of the severe acceleration pulses.

\section{Local Microzone Networks}

In order to check for microzone effects a group of 7 type MO1 and MO2 accelerographs has been installed in the Hutt Valley. Three of these are on rock sites, two being at the foot of the Western hills and one at the foot of the Eastern hills. The remaining 4 are on alluvium of varying depth as shown in Fig。 3(b). There is also a network of 9 type MO2 accelerographs in the wellington area of which 4 are on rock sites as shown in Fig. $3(\mathrm{a})$. The choice of the locations for these accelerographs is based upon geological information on the areas. The present programme of small earthquake measurements may result in some changes of accelero. graph locations or in the use of some further locations. A group of 3 instruments is insta11ed at ground level near the centre of Auckland city, Fig. $3(\mathrm{c})$.

The crucial function of the strong-motion microzone networks of accelerographs is to measure the character of the earthquake attack when the ground is under severe seismic loads, which may induce large reductions of ground stiffness, ground hysteresis losses, and which may possibly cause severe ground damage.

\section{Strong-Motion Accelerographs in Buildings}

During the past three years 8 sets of accelerographs have been installed in buildings in the Wellington, the Auckland and the Christchurch areas. When the last two of these sets are completed there will be 8 buildings with sets of accelerographs interconnected for simultaneous starting and common time marks. About 14 years ago a 10 -storey building was equipped with 7 accelerometers at 5 sites and a central recorder. Despite some problems with the standby electrical power the system has operated successfully during all but one of the larger earthquakes since its installation. The building normal modes and periods were measured with a building shaker and the measured earthquake responses have been consistent with this measured dynamic character of the building. Table II summarises the buildings at present instrumented.

Measured building responses during severe earthquakes will make our understanding of their earthquake resistance much more quantitative. While considerable information on the overload characteristics of some building types, e.g. frame buildings, can be obtained by laboratory tests, these tests are much more difficult for many other building types, e.g. those with large towers and those with shear walls. Even for frame buildings the distribution of damage is often quite different from that assumed during design. For many forms of construction the only practical method of overload test is to measure the response during an actual earthquake.

Again many foundation systems act as a whole, or the components of the foundation interact during their resistance to earthquake attack, and therefore a quantative check again

\section{Accelerograph Networks on Dams}

There are 7 type MO2 accelerographs on the major earth dam at Matahina. These systems are not interconnected.

The problem of assessing the earthquake response of an earth dam is intermediate between that of assessing a microzone area and that of assessing a building. The geometry and materials are well defined and the most important normal modes are also well defined. The main source of energy loss during small vibrations is wave propagation into the supporting ground which is also the case for an area of flexible ground. The most practical method of measuring the dynamic character under small strains is by recording during frequent smal1 earthquakes。 However, the dynamic character of an earth dam subject to large strains can only be measured effectively by strong-motion earthquake recorders, as is the case for ground microzones.

\section{Possible Developments in Strong-Motion Recording}

It is evident that an increased number of accelerographs in the New Zealand-wide network and an increased number of buildings containing accelerographs is desirable. However, adequate maintenance and servicing of such instruments is essential. Service visits should be at about 6-month intervals。 This involves an annual expense of about $10 \%$ of the installed value of the instruments, which is considered reasonable.

To permit the integration of accelerograms to obtain displacements horizontal tilt meters should be included in some accelerographs.

Earthquake displacements of the ground are required for the design of long structures and for the assessment of ground plasticity。 Building displacements give a more direct measure of building plasticity than is given by building accelerations.

Interconnection of $10 c a l$ accelerograph networks will increase the information which can be obtained from an earthquake event, particularly with regard to wave propagation effects.

A more economical method of digitising accelerograms is required, and should if possible be fully automatic.

It is evident that ground measurements which lead to quantitative values for the earthquake attack, and structural measurements which lead to quantitative values for struct. ural resistance to earthquakes are complementary activities which should as far as possible be kept in balance.

\section{References}

Skinner, R. I., Duflou, P. C., Type MO2 Accelerograph, Installation and Operating Manua1. refer to manufacturer; Victoria Engineering Limited, Gregory Street, Lower Hutt, New Zealand.

Skinner, R. I., Duflou, P. C. J., 1965: New Strong-Motion Accelerographs, Proc. Third World Conference on Earthquake Engineering, 
TABLE II

\begin{tabular}{|c|c|c|c|c|c|c|}
\hline Building & & $\begin{array}{c}\text { Lateral Resisting } \\
\text { System }\end{array}$ & Accelerographs & Storeys & Ground & Date Installed \\
\hline $\begin{array}{c}\text { Gordon Wilson } \\
\text { Flats }\end{array}$ & $z_{1}$ & R. C. Shear Walls & 5 interconnected & 10 & Rock and Clay & 1956 \\
\hline Challenge House & 尊 & $\begin{array}{l}\text { 6-storey shear walls } \\
16 \text { storey frame }\end{array}$ & 4 interconnected & 22 & Rock & 1968 \\
\hline Vogel Building & $\sum_{1}^{2}$ & Central R. C. Tower & 4 interconnected & 14 & Gravels \& Clay $\left(400^{\prime}\right)$ & 1969 \\
\hline G.P.O. Building & the & Stee1 Frame & $\begin{array}{l}2(+2) \\
(\text { interconnected })\end{array}$ & 12 & Marine Sediments & 1970 \\
\hline Dalmuir House & 3 & $\begin{array}{l}\text { Deep member } \\
\text { R. C. Frame }\end{array}$ & $\begin{array}{l}2(+1) \\
(\text { interconnected) }\end{array}$ & $15+2 B$ & Rock & 1970 \\
\hline $\begin{array}{l}\text { Auck. Savings } \\
\text { Bank }\end{array}$ & $\begin{array}{l}A_{1} \\
z_{4}\end{array}$ & R. C. Frame & 3 interconnected & $14\}$ & Waitemata & 1969 \\
\hline $\begin{array}{l}\text { Auck. Civic } \\
\text { Center }\end{array}$ & +1 & Steel Frame & 6 & $22\}$ & Siltstone & 1968 \\
\hline $\begin{array}{l}\text { A.U.C. Science } \\
\text { Block }\end{array}$ & b & Twin Towers & 5 interconnected & 10 ; & & 1969 \\
\hline $\begin{array}{l}\text { C.U.C. Science } \\
\text { Block }\end{array}$ & 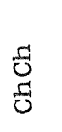 & Shear Walls & 3 interconnected & 8 & Gravels & 1968 \\
\hline
\end{tabular}


Fig. 1.

Locations of type MO Accelerographs.

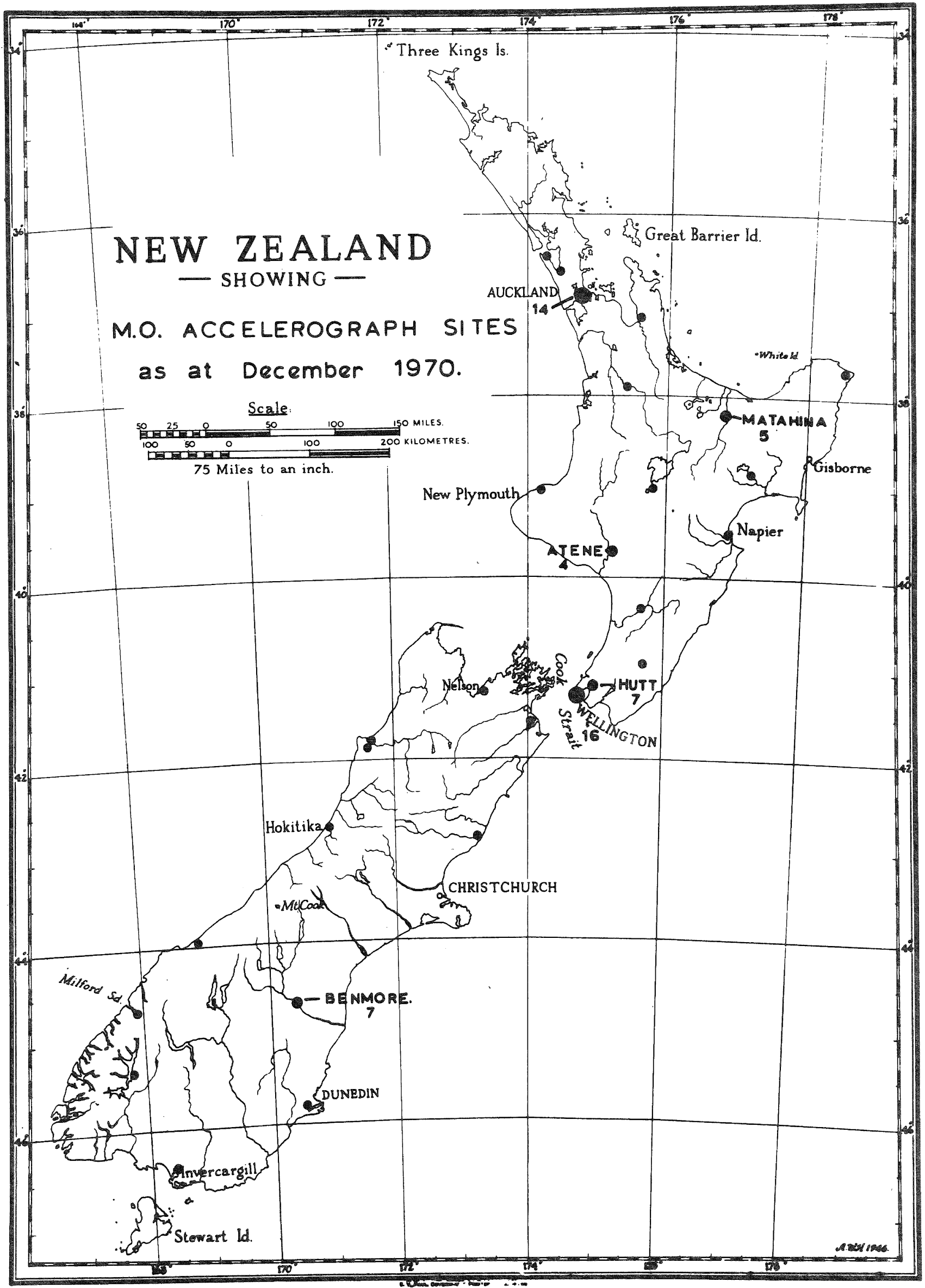


Fig. 2.

Location of type SP Accelerographs

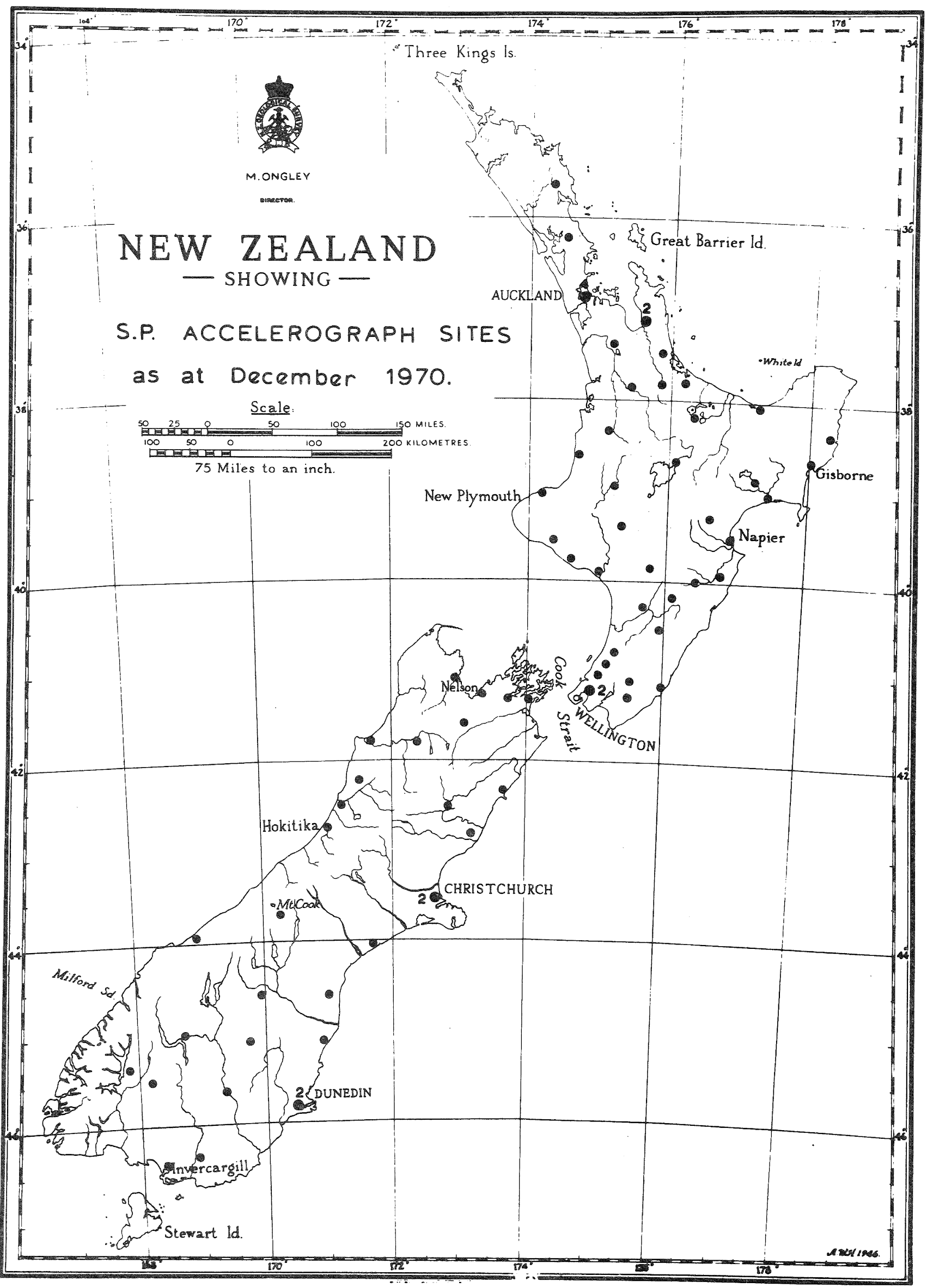


Fig. 3(a).

Location of type MO Accelerographs in the Wellington network.

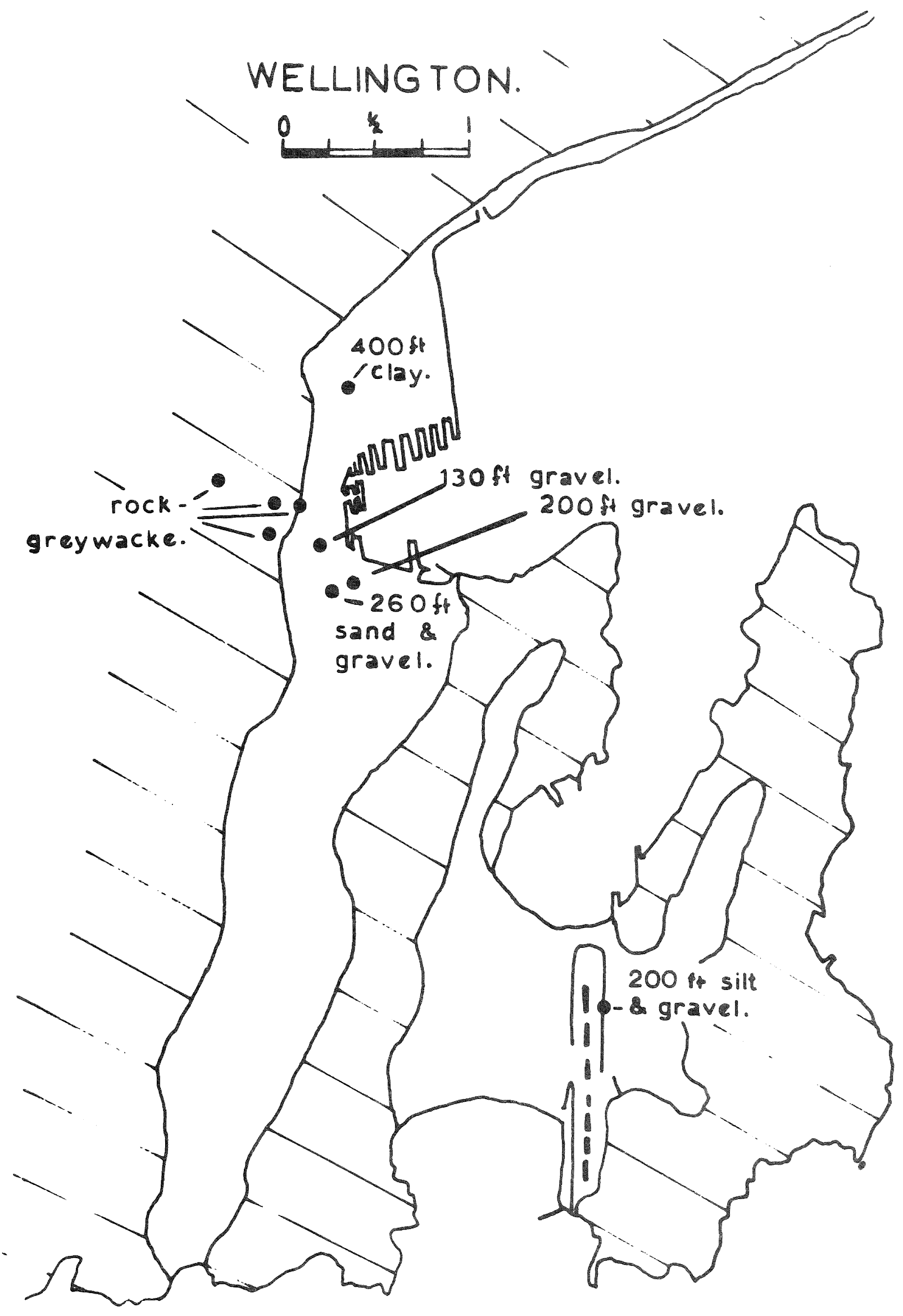


Fig. 3(b).

Location of type MO2 Accelerographs in the Hutt Valley network.

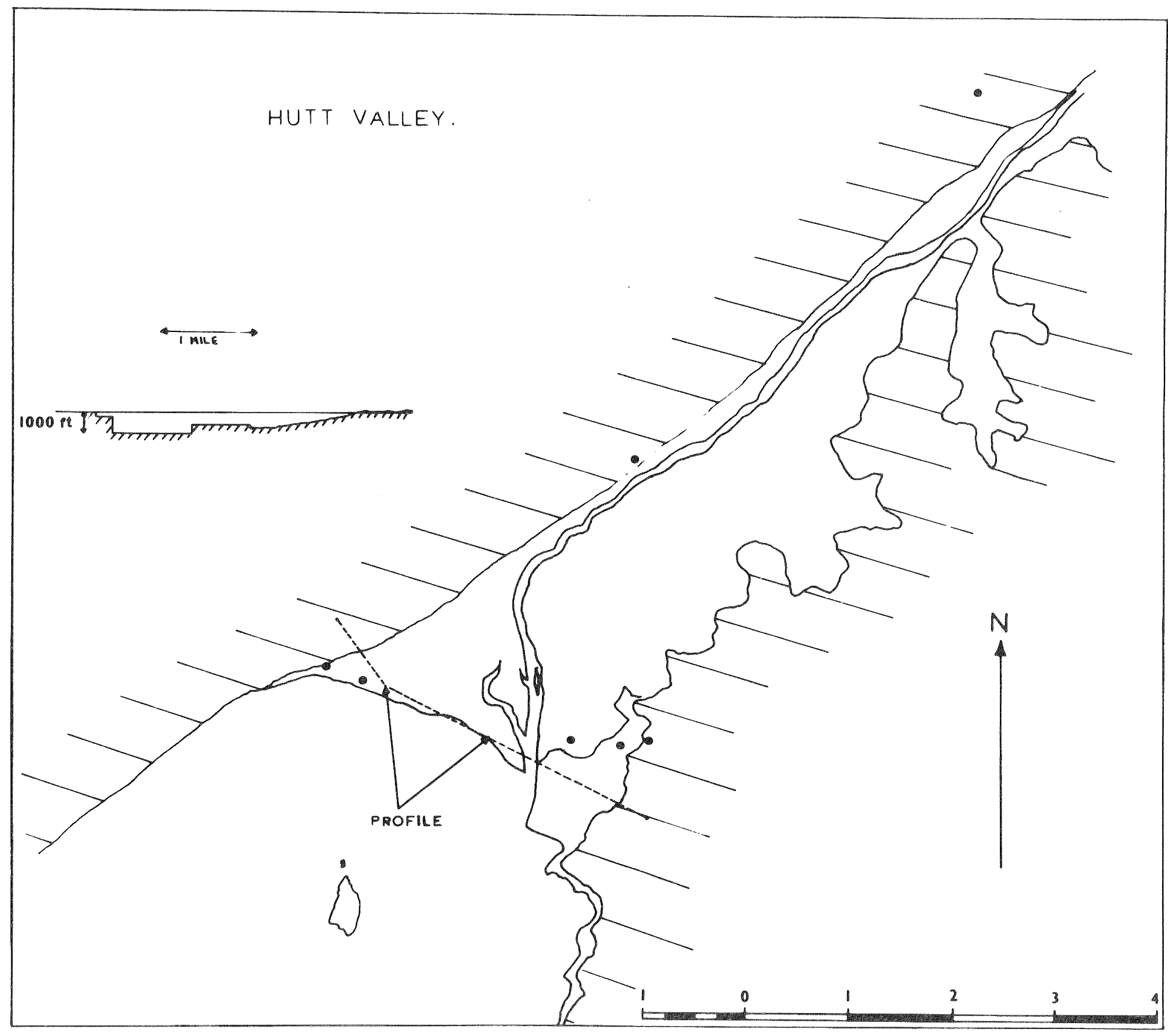


Fig. 3(c).

Locations of ground level Accelerographs in Central Auckland.

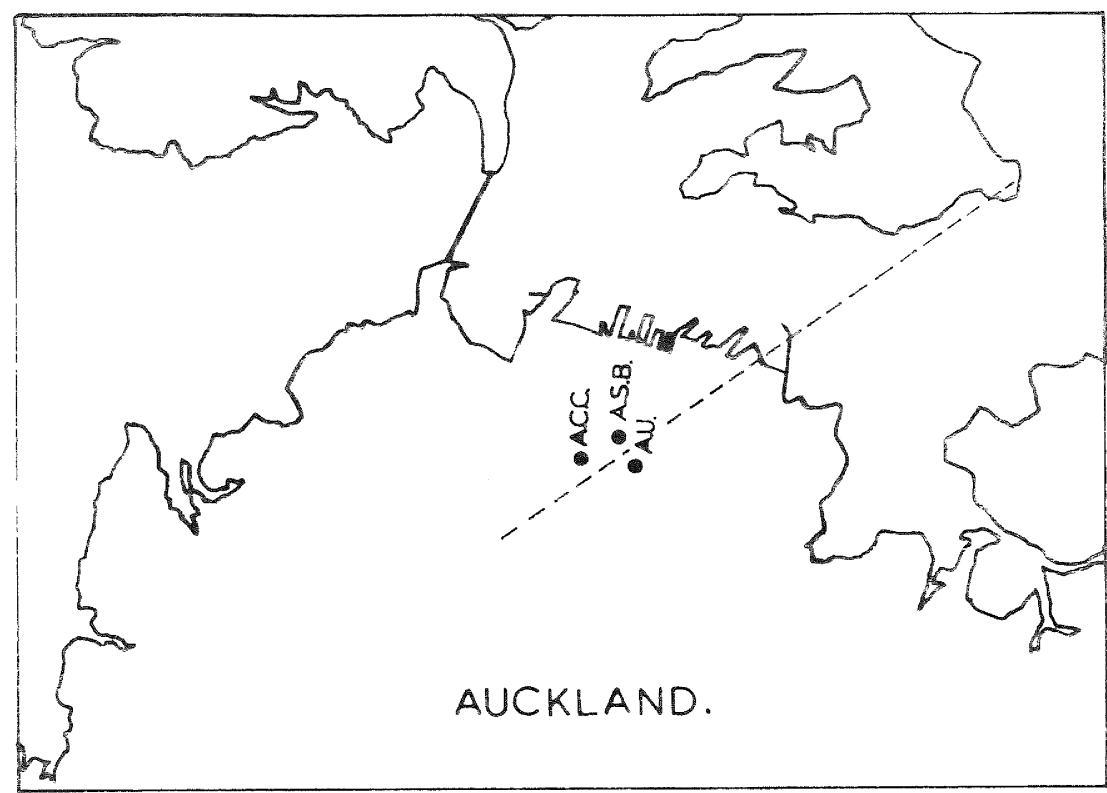

Protile.

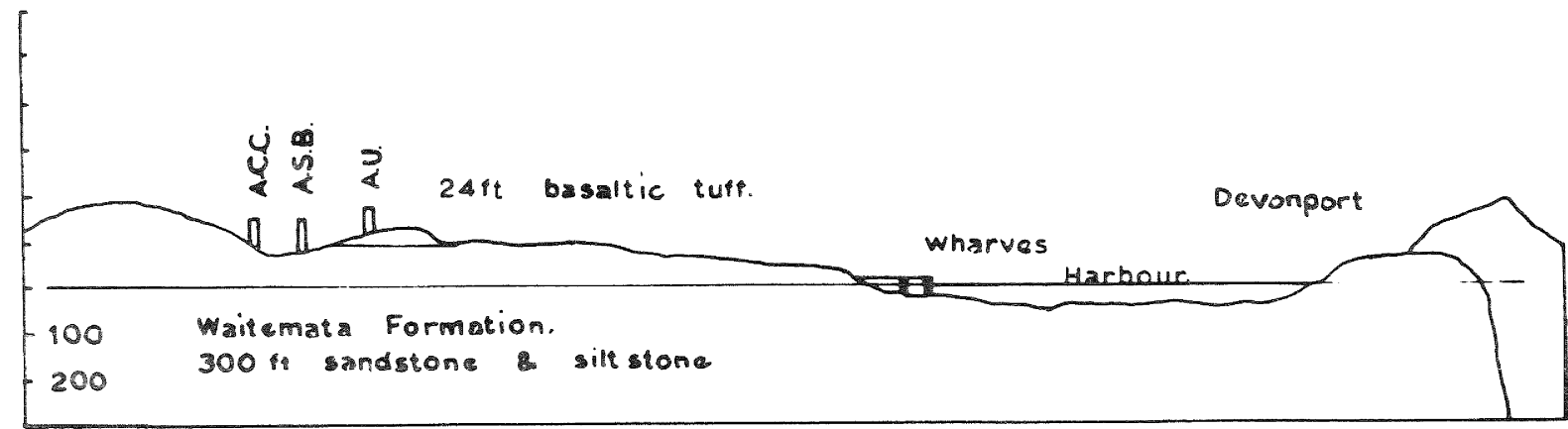

AUCKLAND - not to seale 


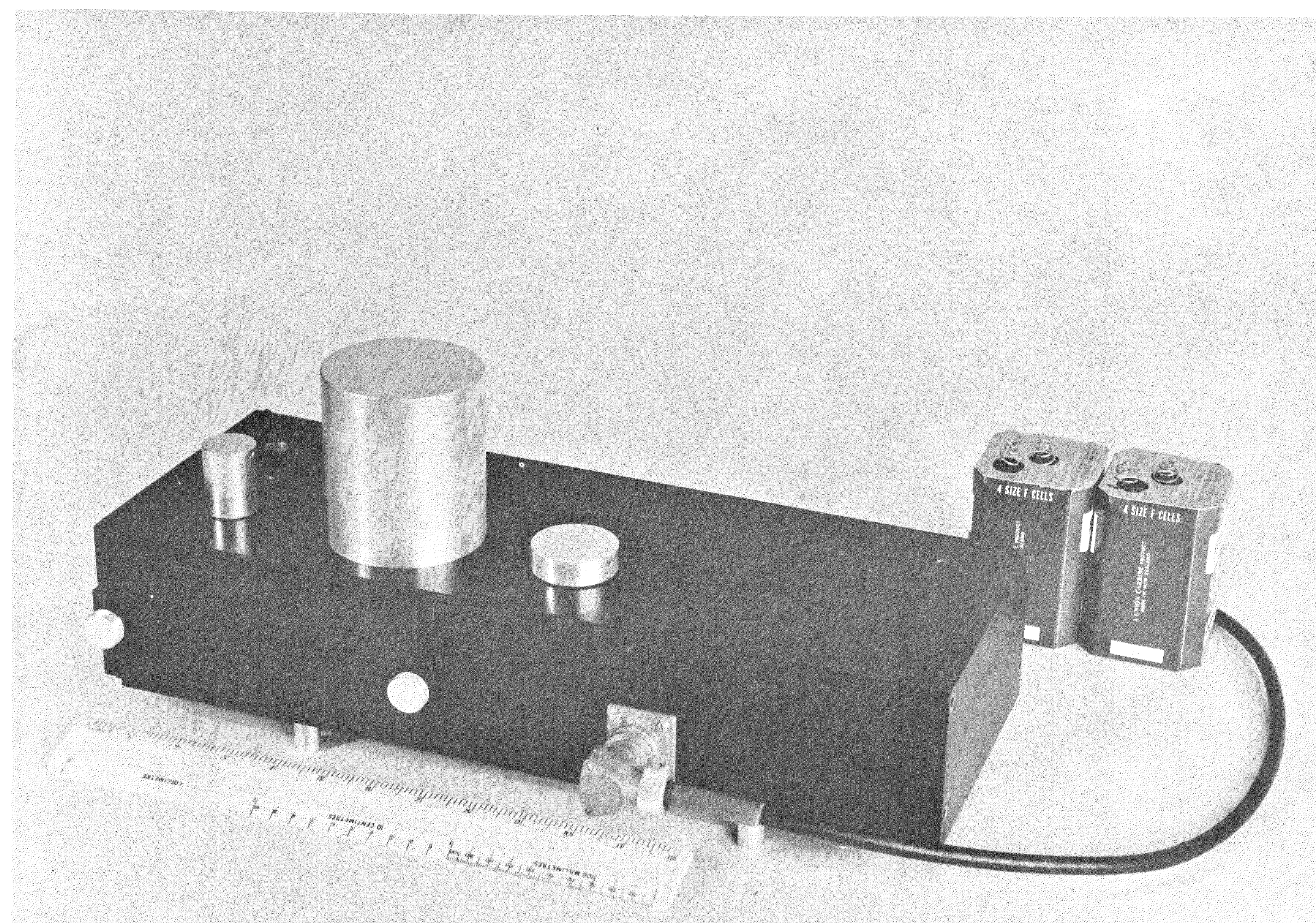




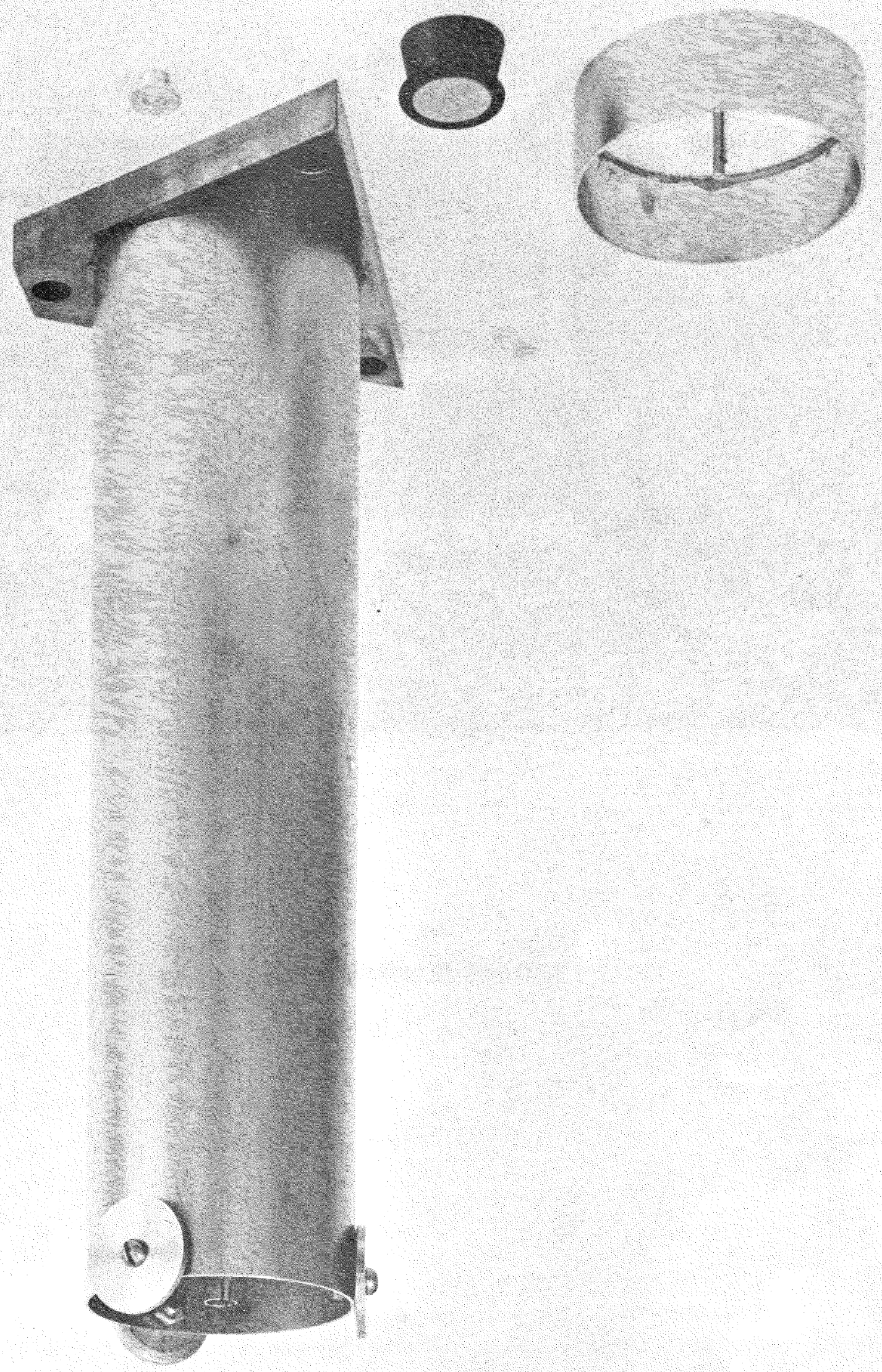

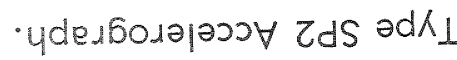

$\cdot(q) \nabla \cdot 6 ! \exists$ 
Fig. 5.

Type MO2 Accelerograph in field site.

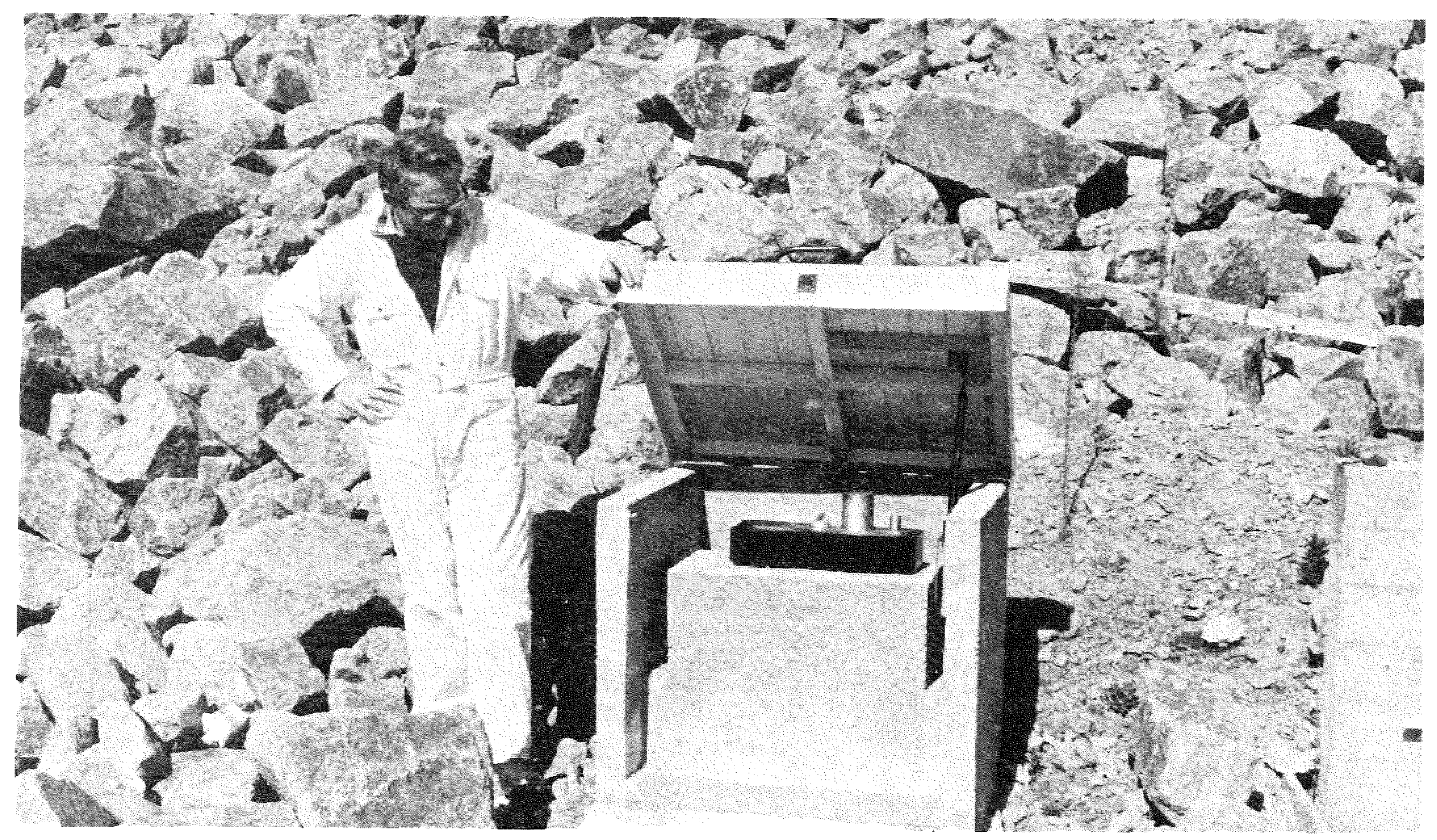

